\title{
Challenges of strategizing the sustainable development of regions in the context of sanctions and restrictions
}

\author{
Tatyana Odintsova*, and Alexander Odintsov \\ Sevastopol State University, Universitetskaya Str., 33, 299053 Sevastopol, Russia
}

\begin{abstract}
The issues of sustainable development of regions and territories acquire special relevance in the context of dynamism and uncertainty of the external environment and trends of social progress, therefore, they are the subject of consideration by a large number of scientists and experts. A condition for ensuring the sustainability of such a development is strategizing, which requires the appropriate information, analytical and methodological support for any region, and even more so for a territory which livelihoods are affected by restrictive international measures. The purpose of the article is to consider the specifics of strategizing the sustainable development of the region, taking into account the influence of the factor of sanctions and restrictions, and to develop the appropriate recommendations for building up a strategy and functioning of the system of its information and analytical support in the appropriate conditions
\end{abstract}

\section{Introduction}

The implementation of the sustainable development concept, in particular at the regional level, is an important condition for the progress of territories, countries and all of humanity, which is confirmed by the serious attention of authoritative international organizations, subjects of state power and management, scientists and experts. The development problem of regional strategizing of socio-economic development includes a number of interrelated parties and aspects.

First, a certain gap can be noted between the theory and practice of the strategic management of the sustainable development of the territories and regions, since often their priority goals and indicators do not fully correspond with the indicators, criteria and methods for assessing the sustainability, to a greater extent being in the plane of the traditional national systems of state management of priorities and measurements.

Second, regional strategizing of the sustainable development presupposes not just a onetime adoption of the target-oriented documents and periodic reporting on the implementation thereof, but a set of the actions to develop a strategy adapted to the regional specifics, constant assessment of its relevance and compliance with the factors of influence

\footnotetext{
*Corresponding author: odintsova06@mail.ru
} 
of a dynamically changing environment, adjustment, monitoring and forming an effective mechanism for implementing the strategy.

Third, in most cases, the weak link in the regional strategic management systems is the lack of a full-fledged feedback mechanism that provides a flexible and prompt response to the behavior of the controlled system and influencing factors, which provides the possibility of the situational and proactive approaches.

Fourth, the system of information and analytical support for the management of the regional sustainable development should be considered as a system that not only supplies an information to the subjects in the contour of the regional management, but also forms an open information environment for all stakeholders, regardless of their status and role in the system of public relations, providing an informational openness of society and the management of the region and is a resource that maintains reputation capital and "advertises" the region through its presence in the global information space and building trust on the part of both "internal" and "external" society, business and the political establishment.

And, finally, there is one more point that should be taken into account when considering the practice of strategizing and its information support: the factor of the vital activity and development of the region under conditions of certain restrictions, as deliberately imposed thereon due to the decisions of a geopolitical or economic nature (for example, international restrictive measures), and natural limitations in the conditions of a shortage of certain resources or lack of the opportunities (inherently associated with the territorial specifics). As S. Kirillov, S. Nikonov and A. Pakina rightly point out [1], the question of finding new models of economic development that minimizes the negative consequences of sanctions and restrictions that reduce access to capital and technology, export earnings is quite acute in regional strategic management and, accordingly, is a significant deterrent. Moreover, the concept of restrictions is not limited to the sanctions or international restrictive measures, they include any factors limiting the life of the territory and its parties, such as most of the measures to prevent the spread of the coronavirus infection, which have highlighted the importance of a situational approach to management.

In general, these problematic moments are not always sufficiently addressed in the special literature, therefore, this article will attempt to consider them in the theoretical and practical aspects, using the example of the system of the regional strategic management of the city of Sevastopol.

\section{Methods and Materials}

The work uses the methods of logical and comparative analysis, expert judgment on the basis of theoretical, cognitive and logical approaches. The information and methodological basis of the article is the works of Russian and foreign authors who consider similar and related issues.

\section{Results and Discussion}

According to the definition of E.I. Levina, "the sustainable development is a process of change in which the exploitation of natural resources, the direction of investment, the orientation of scientific and technological development, personal development and institutional change are coordinated with each other and strengthen the current and future potential to meet human needs and aspirations" [2]. A.I. Gavrilov among the main goals of the socio-economic development of the region, emphasizes the improvement of the quality 
of life of the population (in particular, an increase in the level of its income, health and education, the degree of freedom and self-respect of people with the imperative of human dignity), the development of production; a progress in the institutional, social and administrative structures of society, in public consciousness, traditions and habits) [3]. According to the World Bank experts, the condition for the sustainable development is the positive dynamics of all assets available to mankind, including natural, humanitarian and traditional physical capital, and the expansion (at least not reduction) of the further possibilities of civilization [4].

An important trend in the sustainable development is the replacement of an industrial society with a post-industrial information society, in which information resources, intangible assets, knowledge, creativity, and human capital become the key capital-forming factors that create an added value. There is a change in the structure of social production, with the greatest concentration of employed people in the non-material sector, individualization of production and consumption, a change in the resource structure of the value created. The spheres of education, science, culture, medicine, media communication, and management technologies are becoming the drivers of the development of countries and territories.

Most of the documents on the sustainable development have the status of "soft legislation", declare goals and vision for the future, and are built on the principle of a threelevel configuration according to the principle "goal - objectives - indicators". Accordingly, to monitor and assess the degree of achievement of goals, it is necessary to use a system of relevant indicators, which, as a rule, include indicators and indices of the sustainable development. They characterize the state, dynamics and main trends in the field of economy, environment and social life at the level of systems of a global, regional, national, local and sectoral scale. Among the most famous integral indices of the sustainable development, in particular, one can point out the Global Competitiveness Index, calculated according to the version of the World Economic Forum, the Sustainable Society Index, which is a combined indicator of the Sustainable Society Foundation, the Environmental Performance Index, defined by the Yale Center for Environmental Law and Policy in partnership with Columbia University and the World Economic Forum; the Human Development Index of the United Nations Development Program, the Happy Planet Index proposed by the New Economics Foundation, the World Bank's Genuine Savings, the Genuine Progress Indicator (GPI), the Index of Sustainable Economic Welfare and a number of others.

The breadth of the indicators' capabilities can be illustrated, in particular, by such an interesting example: the Biesiot indicators (the ratio of the response rate to a threat to the rate of spread of this threat) allow one to quantify the stability of the system and can be a good indicator of the stability of the countries and territories against the threat of the coronavirus infection spread.

A significant part of such indicators is applicable at the regional level and can form the basis for assessing the sustainability of the development of individual territories, while, in most cases, existing approaches and indicators are simply adapted in the local aspect. A lot of studies by Russian and foreign scientists, developments of international organizations, rating agencies, and audit companies have been devoted to the possibilities of their application at the regional and municipal levels. For example, one can note the development of the index of sustainable development of cities by GSM agency, the methodology for assessing the rating of cities by Ernst \& Young, and a number of others. S.N. Bobylev and O.V. Kudryavtseva, for example, propose a system of indicators for assessing the sustainable development of cities of 25 indicators, as well as the urban sustainability index based on the concept and methodology for calculating the adjusted net savings index of the World Bank, where gross fixed capital formation is adjusted for the 
amount of budgetary spending on human capital development and damage from the environmental pollution [5]. Analyzing the approaches to assessing the sustainable development in the regional aspect, A.M. Ozina and Sergeeva Yu.V . note that depending on the vector of socio-economic development of the region, indicators can be focused on survival, stabilization of the situation, overcoming depression, or progress, their threshold values should be differentiated taking into account regional specifics and the controllability of the process of ensuring sustainability is provided on the basis of the monitoring indicators of the sustainable development in dynamics, which allows you to timely receive the signals about the possible threats and develop adequate management decisions to prevent them [6].

The development of the regional strategy is largely based on an analysis of factors of the external and internal environment, in particular, resource potential, territorial geographic, geopolitical, economic and socio-cultural characteristics, competitive advantages, risks, bottlenecks and restrictions. The limitations that need to be taken into account in its formation and assessment can be of a very diverse nature and include, in particular, limiting factors of a natural-geographical and geopolitical nature, resource, infrastructural, institutional, financial-economic, demographic and other character. They affect the potential and opportunities for the development of the territory mainly negatively, although in some cases, there is a reverse effect due to the compensatory policy, when the limitations of some factors stimulate additional use of the opportunities for return from others.

In the context of the geopolitical situation of the recent years, an increasingly prominent place among the restrictions is taken by international restrictive measures, associated, in particular, with the political confrontations, trade wars, global competition, attempts to redistribute markets and create a multipolar economic world order. Such measures can be of the nature of sanctions declared at the level of the political establishment, or of a hidden (half-hidden) one and not officially published nature. Table 1 suggests a classification of the limiting factors.

Table 1. Classification of the limiting factors of the regional development.

\begin{tabular}{|c|c|}
\hline Classification attribute & $\begin{array}{l}\text { Type of limiting } \\
\text { factors }\end{array}$ \\
\hline Origin & $\begin{array}{l}\text { External } \\
\text { Internal }\end{array}$ \\
\hline Character & $\begin{array}{l}\text { Naturally occuring (geographic, natural, demographic) } \\
\text { Sociocultural } \\
\text { Political } \\
\text { Economic (resource, infrastructure, } \\
\text { innovative and technological, structural and sectoral, } \\
\text { production and technical, foreign economic) } \\
\text { Institutional }\end{array}$ \\
\hline Duration of exposure & $\begin{array}{l}\text { Temporary } \\
\text { Permanent }\end{array}$ \\
\hline $\begin{array}{l}\text { Nature of } \\
\text { origin }\end{array}$ & $\begin{array}{l}\text { Immanent } \\
\text { Historically established } \\
\text { Situational and behavioral }\end{array}$ \\
\hline $\begin{array}{l}\text { The degree of influence of strategizing } \\
\text { measures thereon }\end{array}$ & $\begin{array}{l}\text { Controlled } \\
\text { Non-controlled }\end{array}$ \\
\hline $\begin{array}{l}\text { Ability to compensate for negative } \\
\text { impacts due to other factors }\end{array}$ & $\begin{array}{l}\text { Compensated } \\
\text { Uncompensated }\end{array}$ \\
\hline $\begin{array}{l}\text { Impact on the development } \\
\text { opportunities }\end{array}$ & $\begin{array}{l}\text { High influence } \\
\text { Medium influence } \\
\text { Low influence }\end{array}$ \\
\hline
\end{tabular}


Table 1. Continued

\begin{tabular}{|c|l|}
\hline \multirow{2}{*}{ Potential risk level } & $\begin{array}{l}\text { High risk } \\
\text { Medium risk } \\
\text { Low risk }\end{array}$ \\
\hline Analogues in the world practice & $\begin{array}{l}\text { Having analogues } \\
\text { Without analogues }\end{array}$ \\
\hline
\end{tabular}

The economic sanctions include the restrictive measures of an economic nature, on the part of one state or a group of states in relation to a certain country/territory in order to force it to change its political course [7]. Sanctions of this kind have a long history and can be varied, although prohibitive trade and financial measures are most often mentioned in the literature. The main difference between the sanctions and the trade restrictions of a protectionist nature is the presence of a political component as a cause of economic pressure over the country - the object of influence - for the purpose of "punishment", forcing to stop or prevent certain actions, including military ones, demonstrations of resolve and strength, attempts to undermine regime, compulsion to change the course. There are many examples of economic sanctions in history, from the ancient world to the modern history; we can mention, for example, such well-known cases as the American embargo against Cuba, the sanctions of the USA, the EU and the G7 countries against Iran due to the Iran-Iraq war and Iran's nuclear program, the sanctions against the Soviet Union due to the restrictions on the emigration of Soviet citizens introduced since 1974 under the JacksonVanik amendment to the US Trade Law, sanctions against the regimes of Fidel Castro, Salvador Allende, Saddam Hussein, Josip Broz ("Tito") and other politically high-profile situations of the use of economic measures of pressure. In addition to economic sanctions, there are instruments of political influence that imply non-recognition or incomplete recognition of countries and territories, as a result of which they exist as subjects with an uncertain political status that do not have full rights in the foreign policy arena and in the global economic world order. Examples are the Turkish Republic of Northern Cyprus, which has existed since 1975 and has not yet been recognized by any country in the world, with the exception of Turkey, the partially recognized Republic of Kosovo, the Donetsk People's Republic and others. In such cases, political isolation entails the economic measures that impede the full functioning of the country or region.

Having an initially economic nature of the impact, the sanctions are not only of the economic, but also of the social consequences, which affects the quality of life of the population and significantly hinders the achievement of those sustainable development goals that underlie modern regional strategy. The modern history of the anti-Russian sanctions that followed the annexation of Crimea is one of the most striking examples of how the restrictive economic measures take a hybrid form and are transformed from purely economic into the comprehensive measures that significantly hinder the socio-economic development from achieving the strategic goals of a territory with a huge potential. With a general negative impact on the economy of the entire country, they have a pronounced local impact on the vital activity of a specific sanctioned territory, affecting not only its economic, but also social, political, infrastructural, reputation and other strategically important areas.

The analysis of the impact of such measures on the development opportunities of the region using the example of the city of Sevastopol allows us to point out the following as their most tangible negative consequences:

- difficulty/impossibility of entering not only the external, but also the domestic Russian market, a reduction in GRP, difficulties in relations with the counterparties, which complicate the material and technical support, sales and normal cooperation processes; 
- limitations and difficulties in resource provision, including not only the high technologies and innovative products, but also the conventional resources (for example, water and electricity);

- low investment attractiveness of the region, which is practically impossible to be increased by natural means of influence, the fear of domestic investors about the investments into areas with a high degree of risk and almost zero opportunities for foreign capital investment, excluding the entities already under the sanctions and representatives of the "toxic" countries;

- negative impact of supporting measures of state influence on the competitiveness of the manufactured products, local business and the territory as a whole;

- partial falling out of the general information space, restrictions on the use of publicly available Internet platforms, digital resources and software products;

- defective functioning of the financial and credit sphere, insurance business, stock market, reduced access to the financial resources, excluding the government investments;

- subsidized nature of the economy, the need for constant investments from the budget in the development of the region and the lack of normal self-sufficiency;

- structural and infrastructural imbalances in the economy associated with an imbalance of resources, limited markets, a given production base and the difficulty of reducing imbalances;

- certain outflow of human capital, especially in terms of graduates of secondary and higher educational institutions, associated with an attempt to fully legitimize the educational documents and expand employment opportunities and career growth;

- restrictions on socially significant freedoms of citizens, such as freedom of movement, recognition of education, unhindered communication, the possibility of free financial transactions, purchases, free self-identification in information retrieval and service systems, etc.

This list is not exhaustive and gives an idea that the normal strategy of not only sustainable, but also full-fledged socio-economic development in such entities and territories is difficult. Since the selection of a strategy for a relatively stable territory and for a territory subject to such the significant risks will be differentiated according to the degree of dependence on the environmental factors, including those of a restrictive nature, it seems appropriate to rely on the following principles when forming the concept of strategizing the development of regions and territories under the sanctions:

- balanced situational approach to the selection of a regional mission and strategy, taking into account the influence of the restrictive measures, realistic forecasts and assessments, maximum departure from the stereotypes and standard solutions, an emphasis on ensuring the vitality and progress of the region's development, and not on declaring the utopian pictures of its future as opposed to the political opponents;

- objective assessment and systematization of the restrictive factors based on the classification proposed above;

- assessment of the planned indicators of socio-economic development based on a scenario approach, taking into account the degree of risk (this approach is to a certain extent implemented in the Strategy for the socio-economic development of the city of Sevastopol [8], but without highlighting the degree of risk from the impact of the restrictive measures);

- assessment of the degree of influence of the restrictive measures over the goal indicators and target indicators, reflecting the degree of the achievement of the strategy, their ranking according to the degree of this impact and the development of the alternative scenarios;

- adjusting the strategy taking into account the impact of the restrictive measures based on a flexible scenario approach; 
- building up an information environment that provides the ability to quickly respond to changes in the development factors.

Also, for such a "sanctioned" region as the city of Sevastopol in the past few years, the presence of the restrictions and risks is a certain factor of influence on the information environment. These limiting factors include the threat of the information blockades and isolation, inadequate communications and interactions, insufficient presence in international economic relations and the global information environment, the forced withdrawal from the transparency and openness of the information space to achieve economic and social short-term effects.

Assessing the information environment of the region, it is necessary to point out a system of information support in its composition for the management of the socioeconomic development of the region, which allows the governing bodies to implement the strategy and monitor the progress of its implementation, a system of information support for economic entities and social institutions, which allows them to make decisions, ensuring the implementation of functional and economic policies at the micro- and meso-level, a system of information and provision of necessary data to the stakeholders and the public. The information support system for the regional development management, on the one hand, forms a complex of information for assessing the degree of achievement of the set goals and objectives, monitoring and analysis of the indicators of the sustainable regional development, on the other hand, it creates an environment of information openness and the image of transparency of data about a given region, creating reputation capital and positive image of the territory.

The level of quality of the information environment in the region, in particular in Sevastopol, can be assessed by a number of the parameters, to which we propose to include the following:

1. Sufficiency of information for decision-making and assessment of the degree of compliance with the strategy at the level of executive authorities, implementation of the corrective actions to manage the activities and adjust the strategy at the regional level.

2. The ability to meet the information needs of not only the government agencies, but also all stakeholders, including any interested institutions and entities inside and outside the region, primarily business, investors and the public.

3. Qualitative characteristics of information, in particular, its reliability, timeliness, sufficiency and completeness of coverage of the main objects of interest to the stakeholders, and relevance as well.

4. Information transparency, which allows assessing the disclosure of information, political culture and the degree of openness of society in a given territory (in particular, in accordance with the concepts of E-Government, eEurope) and shaping the competitiveness and image of the territory. The degree of information openness, in particular, allows one to assess the readiness indices for the use of e-government, determined according to the UN Global E-Government Readiness Report, the CLEAR opacity indices, calculated according to the PwC method [9].

5. The degree of digitalization of information flows, the development of digital infrastructure and the use of information and communication technologies (within the framework of the concepts of the digital economy and the information society). The strategy for the development of the information society in the Russian Federation for 2017 2030 involves the development of data openness and the coverage of information and communication technologies in all spheres of life based on the digital infrastructure [10].

To assess the quality of the information environment in the region, it is proposed to use a profile in which each of the criteria, based on a survey of the respondents, points from one to five are assigned, which will identify the weaknesses as the areas of the increased attention (Table 2). 
Table 2. Profile of the assessment of the information environment of the regional development of the city of Sevastopol

\begin{tabular}{|c|c|c|c|c|c|}
\hline \multirow{2}{*}{ Criterion } & \multicolumn{5}{|c|}{ Point } \\
\cline { 2 - 7 } & $\mathbf{1}$ & $\mathbf{2}$ & $\mathbf{3}$ & $\mathbf{4}$ & $\mathbf{5}$ \\
\hline $\begin{array}{c}\text { Sufficiency of information at the level of the } \\
\text { authorities }\end{array}$ & & & & & \\
\hline Meeting the information needs of the stakeholders & & & & & \\
\hline Qualitative characteristics of information & & 0 & & & \\
\hline $\begin{array}{c}\text { Information transparency } \\
\text { The degree of digitalization of the information } \\
\text { flows }\end{array}$ & & & 0 & & \\
\hline
\end{tabular}

In our opinion, the disadvantages or weaknesses of the existing system of information and analytical support for the strategic development of the region include as follows:

- lack of a unified information environment that provides an opportunity to freely obtain information on the sustainable development of the region for all the stakeholders;

- preferential orientation to information requests of the users, which are the power structures;

- discrepancy between planned and reporting information of a strategic nature;

- using only certain information channels and sources that are specific in processing, presentation format and the nature of the calculated indicators (such as official statistics);

- insufficient information coverage of all spheres of the economic and social life of the region;

- different format of the strategic plans and reports;

- dispersion of the information support system between the performers, the absence of a single unit responsible for information and analytical support of the strategic management of the region;

- the difficulty of monitoring the compliance with the strategy;

- the complexity of applying the situational management, adjusting the strategy depending on the changing factors of the external and internal environment.

\section{Conclusions}

Thus, the important components of the strategic management system for the sustainable development of the region under the conditions of sanctions and restrictions are as follows:

- Determination of the mission and vision of the region in the national and world system, taking into account the geographical, natural, historical, cultural, ethnic, economic and socio-humanitarian characteristics, appropriate positioning and definition of the key goals for the sustainable development of the region;

- Conducting the strategic analysis, taking into account the environmental factors, including limiting factors and sanctions, assessing the degree of their influence, risk, compensatory measures and corresponding development drivers; flexible adjustment of goals;

- Elaboration of goals and objectives of the sustainable development of the region, taking into account the restrictive factors based on a scenario approach and a proactive management model, selection and approval of a system of criteria and indicators that allow monitoring the achievement thereof;

- Determination of the target image of the region based on an assessment of its vision by different groups of the stakeholders in the context of the restrictive measures (the world community, geopolitical allies, economic partners, adjacent territories, market actors, population, business, government institutions, civil society institutions and others); 
- Generation of a system for monitoring the indicators of the sustainable socioeconomic development, operational analysis and control of deviations in order to adjust the activities based on the responsibility of the relevant institutions and structures for ensuring the achievement of the target indicators;

- Generation of an information and analytical environment that ensures the management of the region and information openness of the society for all the stakeholders, which is a resource that supports reputation capital and "advertises" the territory through its presence in the global information space and the formation of trust on the part of society, business and the political establishment, both outside and within the region.

\section{Acknowledgements}

The paper has been prepared within the framework of the "Scientific and methodological foundations of managing the economic development of the region under sanctions" research (reg. No. 38/06-31), carried out at the expense of the internal grants for scientific research of Sevastopol State University (order No. 556-p dated 14.04.2020).

\section{References}

1. S. Kirillov, S. Nikonorov, A. Pakina, European Journal of Sustainable Development, 8(3), 52 (2019)

2. E.I. Levina, Bulletin of Tambov University. Series: Humanities, 11, 113 (2009)

3. V.I. Gavrilov, Regional economics and management, http://vasilievaa.narod.ru/

4. Where is the Wealth of Nations? Measuring Capital for the 21st Century. World Bank, Washington DC, (2006)

5. S. Bobylev, O. Kudryavtseva, Economy of Region, 3, 101 (2014)

6. A.M. Ozina, Yu.V. Sergeeva. Regional problems of economic transformation, 10 (60), $22(2015)$

7. A. R. Ermakov, I. B. Romashova, N. Yu. Dmitrieva, Economic Consultant, 3 (27), 116 (2019)

8. Order of the Government of Sevastopol dated 2.08.2018 No. 233-RP "On approval of the action plan for the implementation of the Strategy for the socio-economic development of the city of Sevastopol until 2030", http://docs-api.cntd.ru/

9. L.N. Orlova, MIR (Modernization. Innovation. Research), 6(4-2), 368 (2015)

10. Presidential Decree No. 203 dated May 9, 2017 "On the Strategy for the Development of the Information Society in the Russian Federation for 2017 - 2030", http://docsapi.cntd.ru/ 